\title{
INFLUENCE OF NANO WOLLASTONITE ON PHYSICAL, ME- CHA NICAL AND MORPHOLOGICAL PROPERTIES OF GYPSUM COMPOSITES MANUFACTURED FROM BAGASSE
}

\author{
Ali Hassanpoor Tichi, ${ }^{1, \$}$, Habibollah Khademieslam², Mojtaba Rezanezhad Divkolae ${ }^{1}$
}

\begin{abstract}
We investigated the effect of adding nano-wollastonite on the physical, mechanical and morphological properties of gypsum Composites. The ratio percentage of bagasse mixing as lignocellulosic material with gypsum at three levels $(85: 15 ; 75: 25 ; 65: 35)$ and nano-wollastonite at three levels of $0 \%, 5 \%$ and $10 \%$. Specimens were prepared according to the standards specifications for the fire resistance (weight loss), mechanical and physical properties. Scanning Electron Microscopy (SEM) were also used to study the properties of composite morphology and distribution of samples. The results showed that by increasing the amount of nano wollastonite, physical and mechanical properties improved. The MOR, MOE and IB of boards decreased with increased bagasse usage amount, and its maximum value was obtained in using $15 \%$ bagasse. The results also showed that increasing the amount of bagasse in boards caused a significant increase in the TS of the boards. The results from microscopic images showed that the optimal level of nano-wollastonite can fill the empty holes and create a uniform structure, thereby improving the properties of the boards.
\end{abstract}

Keywords: Bagasse, density, internal bonding, modulus of rupture, nano wollastonite.

\section{INTRODUCTION}

Gypsum board is an inorganic-bonded panel produced from wood chip and agricultural waste (bagasse) using gypsum as adhesive. It has been primarily used for residential construction, such as wall and roof sheathing. A good building construction material, gypsum board does not emit formaldehyde and also has features high resistance to fire (Deng and Furuno 2001).

Properties of gypsum particleboard reinforced with polypropylene fibers showed that the addition of PP fibers reduced the IB, MOR, MOE and increased the thickness swelling of gypsum board (Deng and Furuno 2001). The physical and mechanical properties of gypsum particleboard reinforced with Portland cement have been examined by Espinoza-Herrera and Cloutier (2011). The results showed that Portland cement incorporation increased the mechanical resistance of the boards.

Agricultural waste that can be used in the gypsum board industry includes rice straw, sunflower stem and bagasse. All of these materials, such as giant reed (Arundo donax), can be used produce different types of composite materials. However, these materials have some negative effects on the properties of composites. Due to high concentration of extractives compared to wood materials, higher inhibitory effects of available extractives in non-wood materials or agricultural residues can be expected on the hydration process of cement

\footnotetext{
${ }^{1}$ Department of Wood Science and Engineering, Technical Faculty of Number 2 (Shahid Hasheminejad), Mazandaran Branch, Technical and Vocational University (TVU), Sari, Iran.

${ }^{2}$ Department of Wood and Paper Science and Technology, Faculty of Natural Resources and Environment, Science and Research

Branch, Islamic Azad University, Tehran, Iran.

•Corresponding author: hasanpoortichi@gmail.com

Received: 26.10.2019 Accepted: 30.04.2020
} 
paste. Presence of these compounds increases the proportion of un-hydrated cement particles and decreases the strength of the cement-bonded particle board (Wei et al. 2003).

It is also possible to increase the reaction speed between gypsum and lignocellulosic material and to reduce the negative effect of extractives by using additives such as calcium chloride and inorganic nanomaterials such as nano-silica and nano-wollastonite. In this study, we used nano-wollastonite to further adapt gypsum to lignocellulosic material. There have been many studies around the world of the effect of nano-wollastonite on wood and composite products, but the effect of nano-wollastonite on gypsum has not been investigated. Commercial grades of wollastonite are typically high in purity. This is due to the fact that almost all manufacturers use wet processing, high-intensity magnetic separation, and/or heavy media separation to remove accessory minerals (Ciullo 1997(. The minerals most commonly found associated with wollastonite are calcite (calcium carbonate), diopside (calcium magnesium silicate), and garnet (calcium aluminum silicate). Wollastonite is hard, white, and alkaline with a $\mathrm{pH}$ of $8+/-1$. It is exploited for its chemistry as a source of $\mathrm{CaO}$ and $\mathrm{SiO}_{2}$, and its low loss on ignition (LOI- Determining the total volatile content), low oil absorption, low moisture absorption, and fire-retarding properties (Ciullo 1997(. The effect of wollastonite has been reported to improve the dimensional stability of solid woods (Haghighi-Poshtiri et al. 2013), and to increase the thermal conductivity coefficient of medium-density fiberboards (MDF) (Taghiyari et al. 2013). Fire-retardant properties of wollastonite have been noted in the literature when it is used in solid wood and wood composite materials (Haghighi-Poshtiri et al. 2013, Taghiyari et al. 2013). Khosrviyan (2009) reported that the physical and mechanical properties of wood-plastic composite were improved with the addition of wollastonite.

Yel et al. (2020) have reported a relationship between press temperatures of $(20,30,40,50,60,70$ and 80$)$ ${ }^{\circ} \mathrm{C}$ on physical, mechanical and thermal properties of cement-bonded particleboard made from the particles of spruce (Picea orientalis) and poplar (Populus tremula). According to their results, the most mechanical and physical resistance of boards were found as $40{ }^{\circ} \mathrm{C}$ for poplar wood and $60{ }^{\circ} \mathrm{C}$ for spruce wood.

Papadopoulos (2008), described that the cement bonded particleboards was resistant to fungi (brown and white rot). fungi failed to attack the cement-bonded boards.

The aim of this research was to study the physical and mechanical properties of a gypsum board. Hence, the effect of using bagasse $(15 \%, 25 \%$, or $35 \%$, with respect to the total content of binder in each mixture), as the replacement of the wood in gypsum system, and also of adding $\mathrm{CaSiO}_{3}$, as additive at nano wollastonite $(0 \%, 5 \%$ or $10 \%$, dry weight basis of cement) to the complex of bagasse-gypsum, on the physical and mechanical behavior of gypsum and properties of the gypsum were examined.

\section{MATERIALS AND METHODS}

\section{Specimen procurement}

The natural gypsum used in this research was purchased from Omid Company (Semnan, Iran). Agricultural waste used in this research was bagasse obtained from Sugar cane workshop (Bahnemir, Iran). Chemical composition of bagasse was in Table 1. Commercial wollastonite was purchased from Vard manufacturing company of mineral and industrial products (Tehran, Iran). Dimensions of the nano wollastonite and specifications of the wollastonite composition are given in Figure 1 and Table 2, respectively. Density wollastonite was $2920 \mathrm{~kg} / \mathrm{m}^{3}$.

Table 1: Chemical composition of bagasse.

\begin{tabular}{|c|c|}
\hline Chemical Compounds & Percentage (\%) \\
\hline Cellulose & 47,6 \\
\hline Lignin & 23,2 \\
\hline Ash & 1,7 \\
\hline Extractives & 4,1 \\
\hline Silica & 0,9 \\
\hline Silica in ash & 42,9 \\
\hline
\end{tabular}




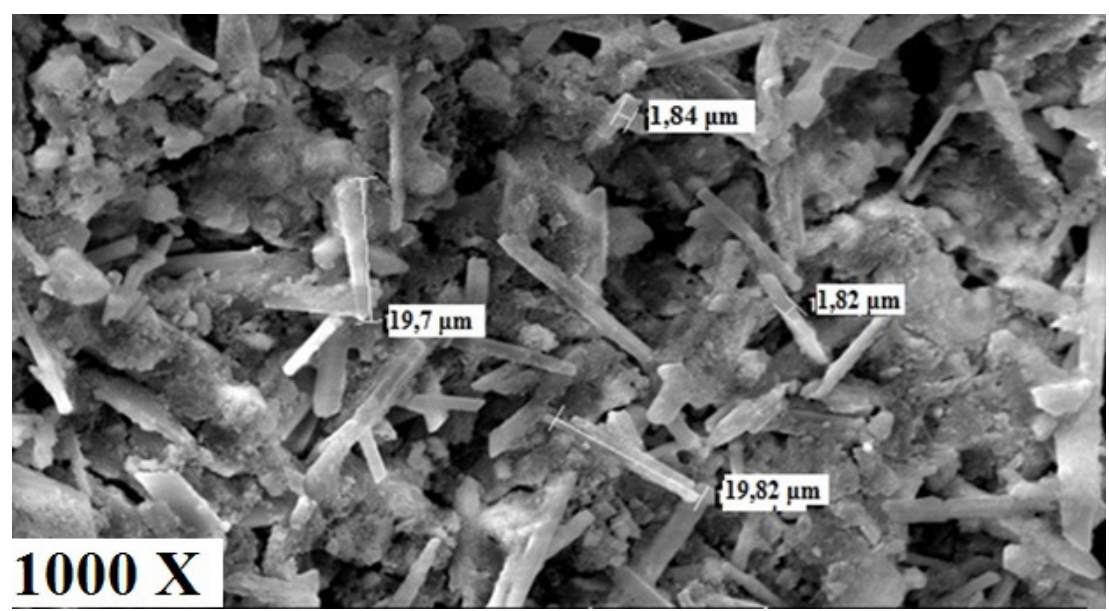

Figure 1: SEM micrograph of nano wollastonite.

Table 2: Composition of the Wollastonite Gel.

\begin{tabular}{|c|c|}
\hline Inorganic component & Percentage (\%) \\
\hline $\mathrm{SiO}_{2}$ & 46,96 \\
\hline $\mathrm{CaO}$ & 39,77 \\
\hline $\mathrm{Fe}_{2} \mathrm{O}_{3}$ & 2,79 \\
\hline $\mathrm{Al}_{2} \mathrm{O}_{3}$ & 3,95 \\
\hline $\mathrm{TiO}_{2}$ & 0,22 \\
\hline $\mathrm{K}_{2} \mathrm{O}$ & 0,04 \\
\hline $\mathrm{MgO}$ & 1,39 \\
\hline $\mathrm{Na}_{2} \mathrm{O}$ & 0,16 \\
\hline $\mathrm{SO}_{3}$ & 0,05 \\
\hline Water & 4,67 \\
\hline
\end{tabular}

Bagasse (Figure 2a) were applied at three proportions $(15 \%, 25 \%$, or $35 \%$, with respect to the total content of binder in each mixture and different wollastonite substitution levels $0 \%, 5 \%$ or $10 \%$ ) for gypsum. The moisture content of bagasse was $50 \%$ before dryer and $6 \%$ after dryer, also oven dry density bagasse was $390 \mathrm{~kg} / \mathrm{m}^{3}$.

\section{Composite panel production}

First, bagasse was washed hot water and then milled into particles using a hammer mill (Figure 2a). Particle size average was $2 \mathrm{~cm}$ to $3 \mathrm{~cm}$ length $1 \mathrm{~mm}$ to $2 \mathrm{~mm}$ thickness. Oven dry density and dimensions of all boards were set at $1100 \mathrm{~kg} / \mathrm{m}^{3} 550 \times 270 \times 20 \mathrm{~mm}^{3}$. Therefore, for the production of boards, the density (oven dry) of raw materials in each treatment was calculated first using density equation. Then the weight ratios of each board were determined (Table 3). Next, using a digital scale, the ratios of water, nano-wollastonite and calcium chloride were determined, and after mixing them in the mixing apparatus (laboratory mixer), these materials were added to the bagasse and gypsum paste that had already been weighted. Subsequently, the cake from the mixing machine was poured uniformly into a $55 \times 27 \times 6 \mathrm{~cm}^{3}$ metal mold and pressed under pressure (Burkle-LA-160) under cold (room conditions for 24 hours at a pressure of $30 \mathrm{~kg} / \mathrm{cm}^{2}$ to reach final thickness $20 \mathrm{~mm})$. After pressing, the boards were kept for 24 hours conditions $\left(20^{\circ} \mathrm{C} \pm 1{ }^{\circ} \mathrm{C}, 65 \% \pm 2 \% \mathrm{RH}\right)$. After initial cooling, the boards were kept in a special chamber at a temperature of about $20^{\circ} \mathrm{C}$ and relative humidity above $90 \%$ for 20 days in order to minimize drying speed. After that, the boards were removed using a circular saw and placed in an air-conditioned room at $20^{\circ} \mathrm{C}$ and $65 \%$ relative humidity for 28 days (Figure $2 \mathrm{~b}$ ). 

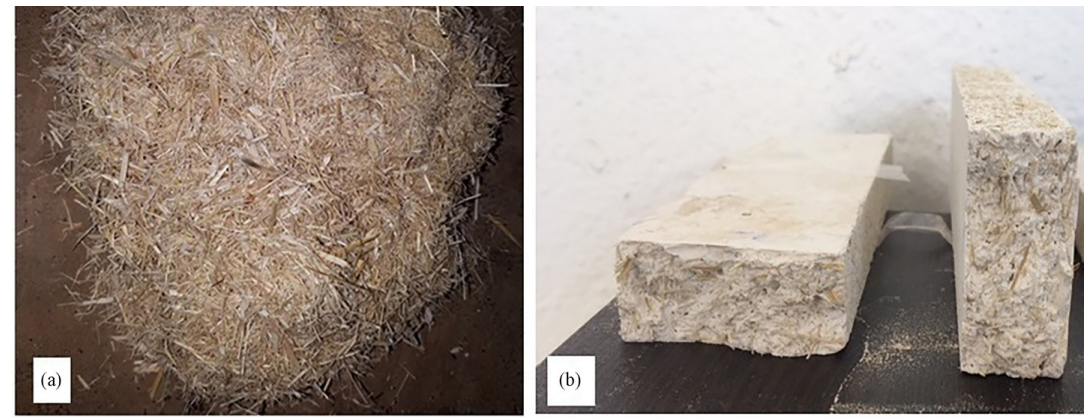

Figure 2: (a) Bagasse chip, (b) Gypsum board with bagasse chip.

Table 3: Weight ratios of each board.

\begin{tabular}{|c|c|c|c|c|c|}
\hline $\begin{array}{c}\text { Nano- } \\
\text { wollastonite } \\
(\%)\end{array}$ & $\begin{array}{c}\text { Gypsum- bagasse } \\
(\%)\end{array}$ & $\begin{array}{c}\text { Bagasse } \\
\text { weight } \\
(\mathrm{g})\end{array}$ & $\begin{array}{c}\text { Gypsum } \\
\text { weight } \\
(\mathrm{g})\end{array}$ & $\begin{array}{c}\text { Nano } \\
\text { wollastonite } \\
\text { weight } \\
(\mathrm{g})\end{array}$ & $\begin{array}{c}\text { Total } \\
\text { weight } \\
(\mathrm{g})\end{array}$ \\
\hline \multirow{3}{*}{$0 \%$} & $85 \%-15 \%$ & 445,5 & 2524,5 & - & 2970 \\
\cline { 2 - 6 } & $75 \%-25 \%$ & 742,5 & 2227,5 & - & 2970 \\
\cline { 2 - 6 } & $65 \%-35 \%$ & 1039,5 & 1930,5 & - & 2970 \\
\hline \multirow{3}{*}{$5 \%$} & $85 \%-15 \%$ & 445,5 & 2398,28 & 126,22 & 2970 \\
\cline { 2 - 6 } & $75 \%-25 \%$ & 742,5 & 2116,125 & 111,375 & 2970 \\
\cline { 2 - 6 } & $65 \%-35 \%$ & 1039,5 & 1833,975 & 96,525 & 2970 \\
\hline \multirow{3}{*}{$10 \%$} & $85 \%-15 \%$ & 445,5 & 2272,05 & 252,45 & 2970 \\
\cline { 2 - 6 } & $75 \%-25 \%$ & 742,5 & 2004,75 & 222,75 & 2970 \\
\cline { 2 - 6 } & $65 \%-35 \%$ & 1039,5 & 1737,45 & 193,05 & 2970 \\
\hline
\end{tabular}

\section{Mechanical and physical tests}

The samples were then evaluated for static banding three points edgewise such as modulus of rupture (MOR), modulus of elasticity (MOE) and internal bonding (IB) according to DIN EN 634-1:1195-04 (1995) using a universal testing machine (model GT-TCS-2000; Taichung Industry Park, Taichung, Taiwan) at the speed of $10 \mathrm{~mm} / \mathrm{min}$. Three replicates were made at a dimension of $550 \times 270 \times 20 \mathrm{~mm}^{3}$ for each board type. Samples dimensions for static banding and internal bonding test were 450 (loading span: $400 \mathrm{~mm}$ ) length $\times$ 50 width $\times 20$ thickness $\left(\mathrm{mm}^{3}\right)$ and 50 length $\times 50$ width $\times 20$ thickness $\left(\mathrm{mm}^{3}\right)$, respectively. For IB test, first, cut the specimens to $5 \mathrm{~cm} \times 5 \mathrm{~cm}$ dimensions and then we glue them to the special jaws of the machine. Next we place the jaws inside the machine. The apparatus applies tensile force to the jaws, causing fractures in the specimen's brain, resulting in the amount of internal bonding being determined (Figure 3).

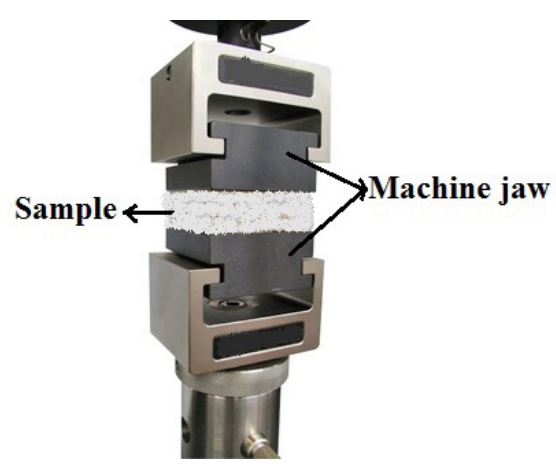

Figure 3: Testing machine for internal banding. 
The load and deflection were continuously recorded and the data were used to calculate modulus of rupture (MOR), modulus of elasticity (MOE) and internal bonding (IB) in based on Equation 1, Equation 2 and Equation 3:

$$
\begin{aligned}
& M O R=1,5 \frac{P L}{b d^{2}} \\
& M O E=\frac{P L^{3}}{4 b d^{3} D} \\
& I B=\frac{P_{\max }}{A}
\end{aligned}
$$

Where $P$ is the maximum force $(\mathrm{N}), L$ is the span length $(\mathrm{mm}), b$ is the sample width $(\mathrm{mm}), d$ is the sample thickness (mm), $D$ is the deflection, $A$ is the felling area $\left(\mathrm{mm}^{2}\right)$.

\section{Physical tests}

The effect of composite formulation on the thickness swelling after 2 and 24 hours immersion in water was determined in samples with the dimensions of $50 \mathrm{~mm} \times 50 \mathrm{~mm} \times 20 \mathrm{~mm}$ according to DIN EN 634-1:1195-04 (1995). Sample was soaked in distilled water for $2 \mathrm{~h}$ and $24 \mathrm{~h}$ (room temperature). TS were then calculated according to the following Equation 4:

$$
T S=\frac{T_{2}-T_{1}}{T_{1}} \times 100
$$
sion.

Where TS is thickness swelling (\%), $\mathrm{T}_{1}$ is thickness before immersing, $\mathrm{T}_{2}$ is thickness after each immer-

\section{Fire-retardant testing apparatus}

The boards measuring 150 length $\times 100$ width $\times 20$ thickness $\left(\mathrm{mm}^{3}\right)$ were prepared according to the ISO 11925-2 (2010) specifications for the fire resistance tests (Figure 4). Mass loss of the samples due to fire exposure was vertically mounted on a holder up-straight and exposed to a Bunsen-type burner (with the internal diameter of $11 \mathrm{~mm}$ ) hold at 45 degrees to the surface of the specimen for 120 seconds in accordance with method described by Esmailpour et al. (2017). Then, the burnt area, as well as weight loss, is measured. From the preliminary weight of specimens before fire exposure $\left(\mathrm{W}_{1}\right)$ and second weight of specimens after fire exposure $\left(\mathrm{W}_{2}\right)$, the Mass loss (ML) was calculated as Equation 5:

$$
\operatorname{ML}(\%)=\frac{W_{2}-W_{1}}{W_{1}} \times 100
$$




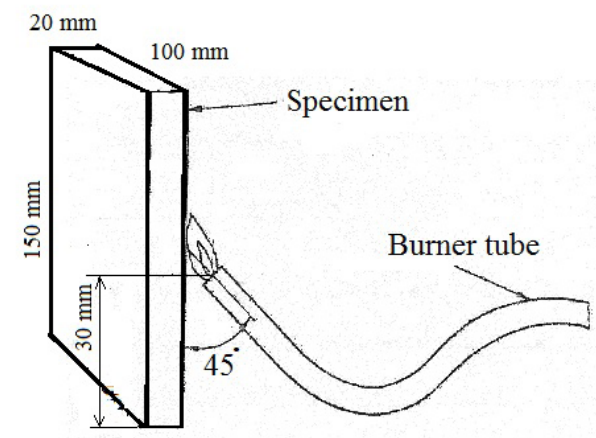

Figure 4: Schematic picture of fixed fire testing apparatus.

\section{Scanning electron microscopy (SEM)}

The fracture surfaces were analyzed from samples fractured in the flexural strength test, using images obtained by scanning electron microscopy. The maximum magnification used here was 3000x. The specimens were cut with dimensions of $10 \mathrm{~mm} \times 10 \mathrm{~mm}$, attached to a sample holder and metallized with gold. The microscope used here was a Philips model XL 30 FEG carried out at the School of Electrical and Computer Engineering, University of Amir Kabir, Tehran, Iran.

\section{Statistical analyses}

Statistical analyses were performed using Statistica software v.13 (Dell Inc. 2016). The obtained results were analyzed statistically, and an analysis of variance (ANOVA) was performed to determine the significance of the tested parameter. A duncan's multiple range test (DMRT) was performed to compare treatment means.

\section{RESULTS AND DISCUSSION}

\section{Mechanical properties of the gypsum boards}

The results from the mechanical testing are shown in Figure 5, Figure 6 and Figure 7. As shown, the MOR, $\mathrm{MOE}$ and IB values increased in the gypsum boards that contained wollastonite compared to the gypsum boards without wollastonite. The highest and lowest modulus of rupture (MOR), values were found in the 10 $\%$ wollastonite and $15 \%$ bagasse chip $(10,8 \mathrm{MPa})$ and $0 \%$ wollastonite and $35 \%$ bagasse chip $(3,25 \mathrm{MPa})$ treatments, respectively (Figure 5). Results of the modulus of elasticity (MOE) tests indicated that the highest (4870 MPa) and lowest (2370 MPa) MOE values were found in the same treatments as the highest and lowest MOR values (Figure 6). The highest and lowest internal bond (IB) values were found in the $10 \%$ wollastonite and $15 \%$ bagasse chip $(2,1 \mathrm{MPa})$ and $0 \%$ wollastonite and $35 \%$ bagasse chip $(0,54 \mathrm{MPa})$ boards, respectively (Figure 7). The abundance of extractive materials in lignocellulosic materials and agricultural wastes, especially phenolic and sugary materials, reduces gypsum hydration heat, slows the hydration reaction time, and increases bagasse retention time (Rangavar et al. 2016). There are several reasons for the increased mechanical properties with increasing nano-wollastonite in the mix. By measuring the hydration heat of gypsum-bagasse slurry and different amounts of nano-wollastonite, it was found that with increasing nano, the hydration heat was increased, which resulted in faster and better curing of bagasse with gypsum and thus increased board strength. Silica in nano-wollastonite forms a calcium silicate hydrate $(\mathrm{Ca}-\mathrm{Si}-\mathrm{H})$ gel, preventing the penetration of chlorine ions, sulfates and other harmful chemicals into boards, increasing durability, increasing hydration heat, speeding gypsum and mechanical strength ( $\mathrm{Li}$ et al. 2004). High substitution levels of wollastonite mitigated the negative effect of the extractive materials (Karimi et al. 2012, Ma and Wang 2012). Consequently, the mechanical properties were improved. 




- bagasse $15 \%$ a bagasse $25 \%$ bagasse $35 \%$

Figure 5: Effect of varying levels of nano wollastonite on the MOR of composites composed of different percentages of bagasse; letters on each column indicate Duncan's grouping at the $99 \%$ level of confidence.

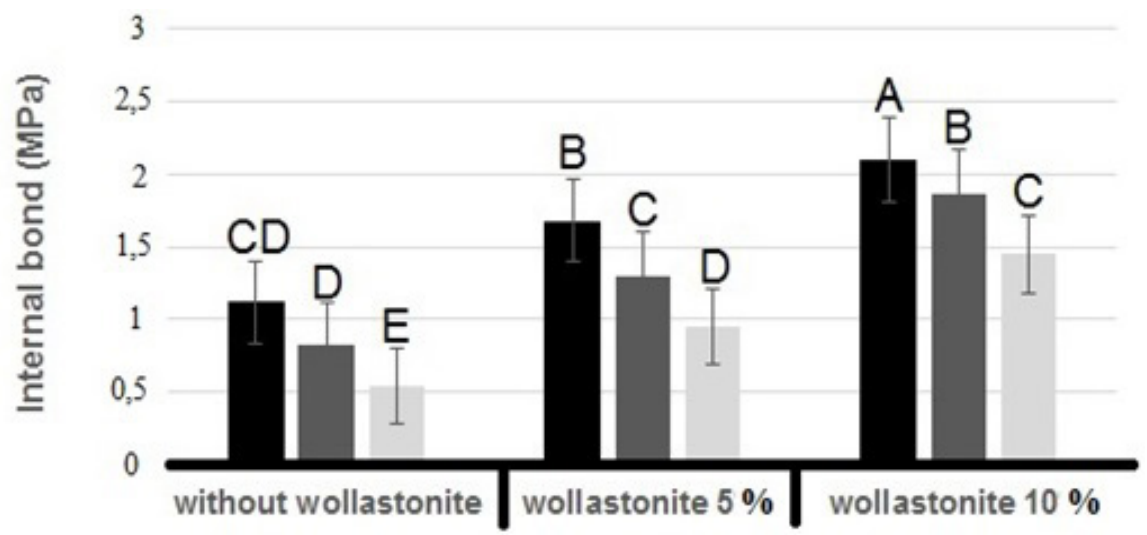

- bagasse $15 \%$ abagasse $25 \%$ bagasse $35 \%$

Figure 6: Effect of varying levels of nano wollastonite on the MOE of composites composed of different percentages of bagasse; letters on each column indicate duncan's grouping at the $99 \%$ level of confidence. 


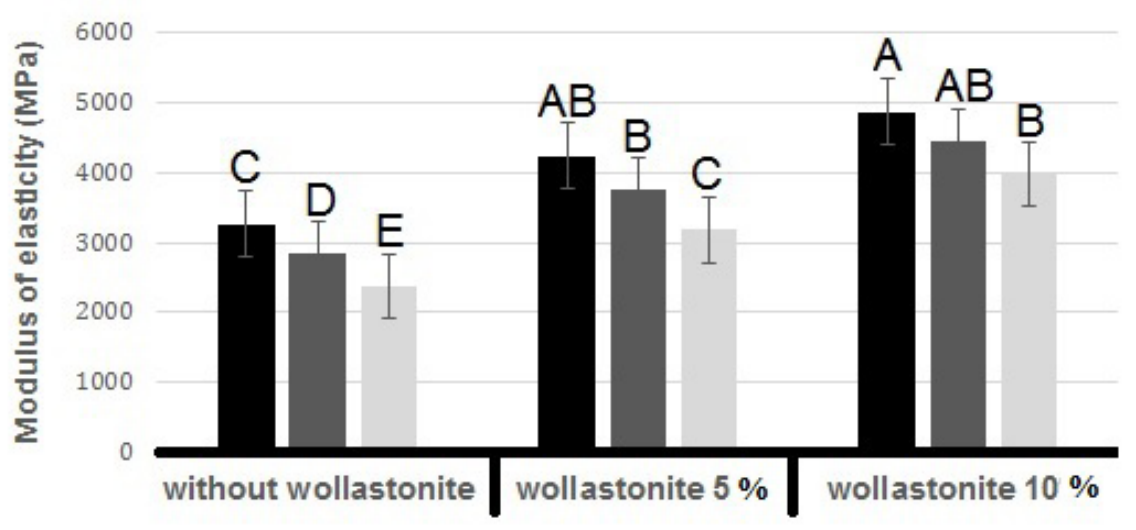

- bagasse $15 \%$ a bagasse $25 \%$ bagasse $35 \%$

Figure 7: Effect of varying levels of nano wollastonite on the IB of composites composed of different percentages of bagasse; letters on each column indicate duncan's grouping at the $99 \%$ level of confidence.

\section{Physical properties of the gypsum boards}

The physical properties of the panels evaluated were thickness swelling after 2 and 24 hours immersion in water, density and fire resistance (Mass loss). The results of these tests are presented in the Figure 8, Figure 9 and Figure 10. Adding nano wollastonite to gypsum board has been shown to decrease the thickness swelling of boards. The lowest thickness swelling was observed for $10 \%$ wollastonite and $15 \%$ bagasse chip, and the highest was observed for the sample without wollastonite and $35 \%$ bagasse chip (Figure 8). Nano-wollastonite addition to gypsum board and increases the density and decreases the air content in boards. The highest density was found in $10 \%$ wollastonite and $15 \%$ bagasse chip, showing $28 \%$ of increase in comparison to the sample without wollastonite and $35 \%$ bagasse chip (Figure 9). One of the reasons can be attributed to biometrics, slimming coefficient, sponge structure and hydrophilic properties of bagasse. It was also observed that with increasing nano, the dimensional stability of the boards improved. The reason for this can be attributed to the hydrophobicity of nano-wollastonite (Ciullo 1997). Nano-wollastonite, due to its high surface area and small size, fills the possible pores inside the board and blocks the water entering the board, thereby reducing the thickness swelling of the board and increasing the density of the board (Hassanpoor-Tichi et al. 2019). Also, with increasing bagasse content in the boards, their density decreased, which is due to the reversal of the thickness swelling of the boards made from higher ratios of this lignocellulosic material. The results of microscopic imaging are a strong reason for this claim (Figure 11). The results indicated that the fire-retarding properties of the samples were improved by the addition of wollastonite (Figure 10). The lowest mass loss was noted with the sample containing $10 \%$ wollastonite and $15 \%$ bagasse chip (Figure 10). The reason we can say this is because, firstly, nano-wollastonite has a high heat transfer $(2,5 \mathrm{w} / \mathrm{m} \cdot \mathrm{K})$ and its heat is not kept at a single point and is rapidly transferred to a point where it has less heat and this causes to reduce the fire proofability of boards and increase their fire resistance (Taghiyari et al 2014), secondly, nano-wollastonite contain silica, titanium, magnesium, calcium and iron that are minerals. This has caused, boards made with higher amounts of nano-wollastonite have higher relative fire resistance. 


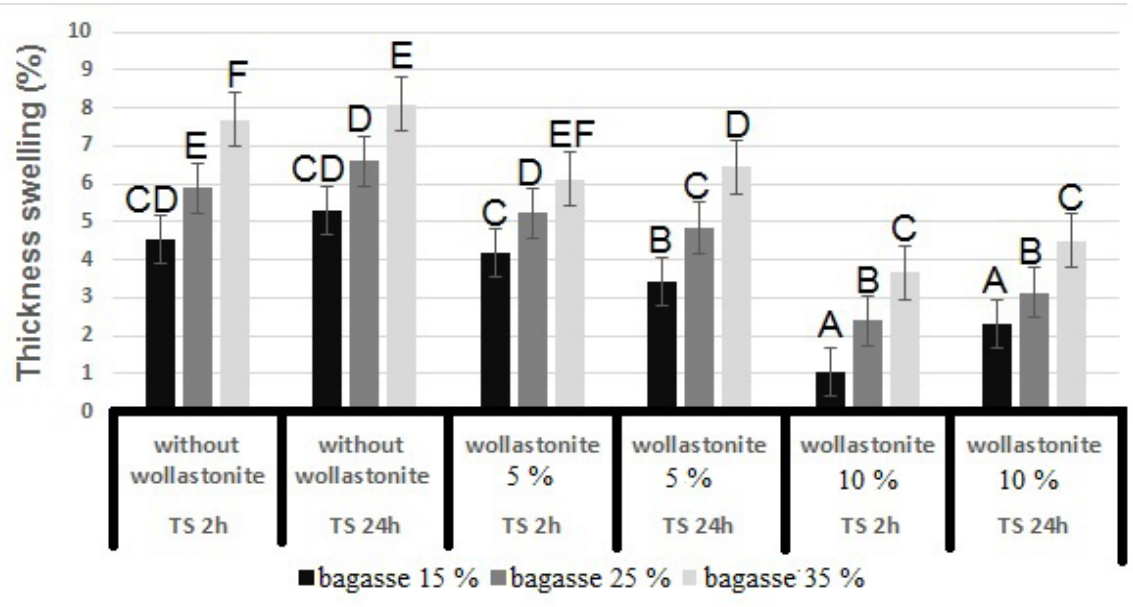

Figure 8: Effect of varying levels of nano wollastonite on the thickness swelling (TS) of composites composed of different percentages of bagasse; letters on each column indicate duncan's grouping at the $99 \%$ level of confidence.

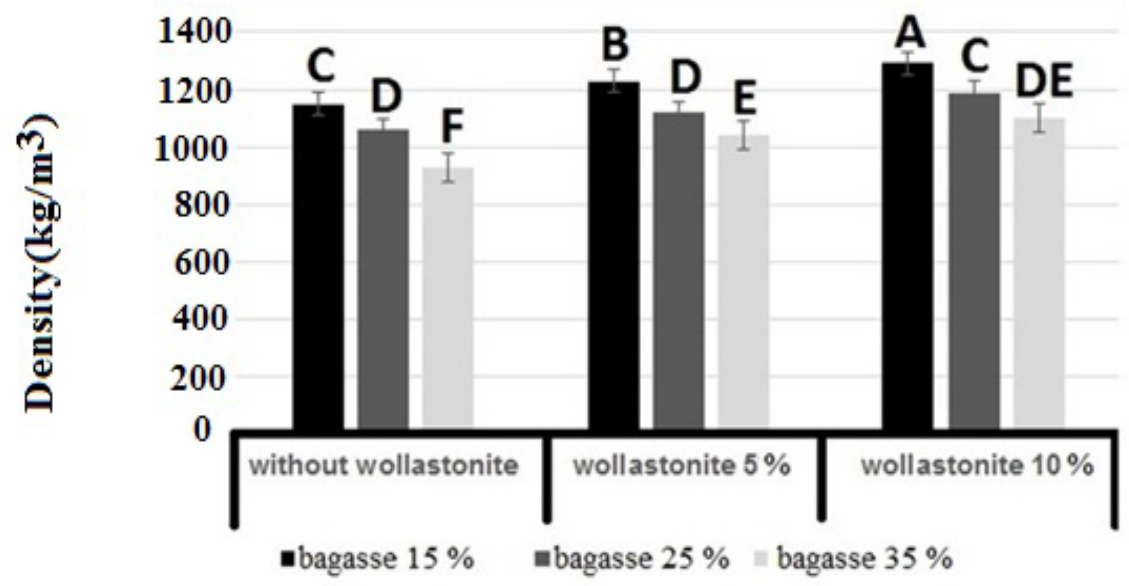

Figure 9: Effect of varying levels of nano wollastonite on density of composites composed of different percentages of bagasse; letters on each column indicate duncan's grouping at the $99 \%$ level of confidence.

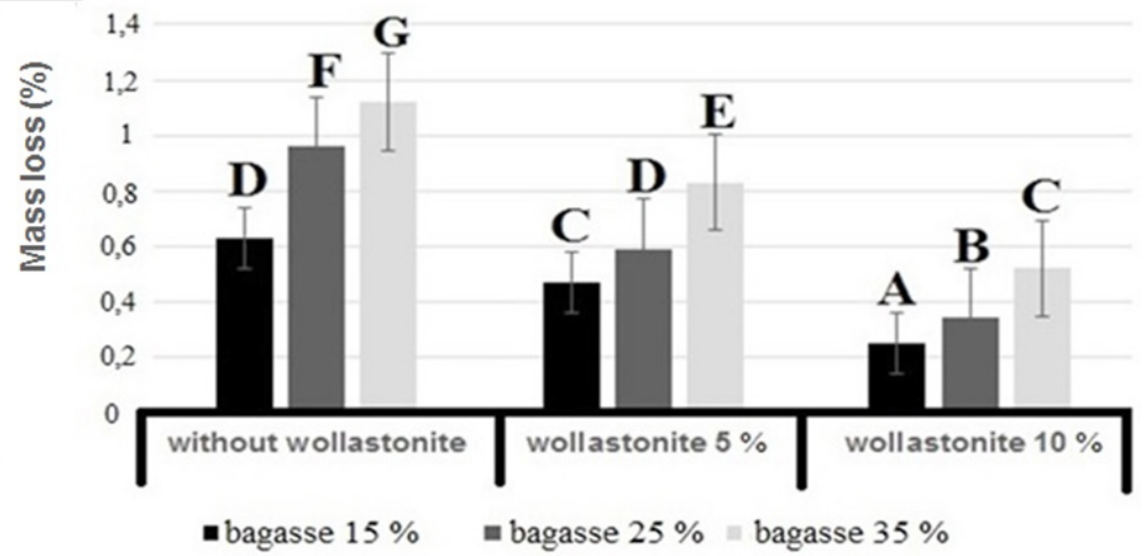

Figure 10: Effect of varying levels of nano wollastonite on Mass loss of composites composed of different percentages of bagasse; letters on each column indicate Duncan's grouping at the $99 \%$ level of confidence. 


\section{Microstructural investigation}

Scanning Electron Microscopy (SEM) was used to investigate the morphology of the fracture surface of boards. Figure 11 shows different amounts of nano-wollastonite. Increasing nano-wollastonite from $0 \%$ to 10 $\%$ improves the adhesion between bagasse and Gypsum, which can lead to higher mechanical and physical strength of boards. Also higher percentages of nano-wollastonite in the boards and reaction of this material with calcium chloride and calcium hydroxide results in high production of hydrated calcium silicate gel (Figure 11a). This gel prevents the penetration of chlorine ions, sulfates and other harmful chemicals into the boards and seals, protects, reduces permeability, durability and self-healing between gypsum and bagasse. The images also show that nano-wollastonite provides a stronger, provides strong bonding between bagasse and gypsum, thus filling the porosity and voids between bagasse and gypsum, thereby increasing the dimensional stability and density of boards. However, as shown in Figure 11a, there is no good bonding between the bagasse chip and the gypsum, and the absence of nanocrystals causes large cavities.



Figure 11: Scanning electron microscopy (SEM) of composite Gypsum- bagasse in the presence of (a) $10 \%$ nano, (b) $5 \%$ nano and (c) without- nano.

\section{CONCLUSIONS}

In based on the findings, mechanical strengths of boards such as flexural strength, modulus of elasticity and internal bonding increased with addition of nano wollastonite content. Increasing nano wollastonite cause decreases the void, moisture content and increasing of composite density. Silica in nano-wollastonite forms a calcium silicate hydrate $(\mathrm{Ca}-\mathrm{Si}-\mathrm{H})$ gel, preventing the penetration of chlorine ions, sulfates and other harmful chemicals into boards, increasing durability, increasing hydration heat, speeding gypsum and mechanical strength. With the increase of nano wollastonite, dimensional stability of gypsum board improved. A reason for this observation could be related to the hydrophobic character of wollastonite. Nano-wollastonite significantly improved fire-retarding properties in gypsum board. The high thermal conductivity of wollastonite increased heat transfer, which improved the fire resistance of the composite boards. Boards made with $15 \%$ bagasse and $10 \%$ nano-wollastonite is recommended to improve the physical and mechanical properties in gypsum board. 


\section{REFERENCES}

Ciullo, P.A. 1997. Industrial minerals and their uses. Noyes Publications, Westwood, USA. 640p. https:// www.elsevier.com/books/industrial-minerals-and-their-uses/ciullo/978-0-8155-1408-4

DIN. 1995. Cement-bonded particleboards - Specifications - Part 1: General requirements. (German version). DIN EN 634-1:1995-04. 1995. Berlin, Germany. https://dx.doi.org/10.31030/2742430

Deng, Y.H.; Furuno, T. 2001. Properties of gypsum particleboard reinforced with polypropylene fibers. $J$ Wood Sci 47(6): 445-450. https://doi.org/10.1007/BF00767896

Dell Inc. 2016. Dell Statistica, version 13. Data Analysis Software System; Dell Inc., Landolock, TX, USA.

Esmailpour, A.; Taghiyari, H.R.; Nouri, P.; Jahangiri, A. 2017. Fire-retarding properties of nano-wollastonite in particleboard. Fire Mater 42(6): 306-315. https://doi.org/10.1002/fam.2493

Espinoza-Herrera, R.; Cloutier, A. 2011. Physical and mechanical properties of gypsum particleboard reinforced with Portland cement. Eur J Wood Wood Prod 69(2): 247-254. https://doi.org/10.1007/s00107-0100434-x

EN ISO. 2010. Reaction to fire tests - Ignitability of building products subjected to direct impingement of flame - Part 2: Single-flame source test. EN ISO 11925-2. 2010. ISO: Vernier, Geneva, Switzerland. https:// www.iso.org/

Hassanpoor-Tichi, A.; Bazyar, B.; Khademieslam, H.; Rangavar, H.; Talaeipour, M. 2019. Is Wollastonite Capable of Improving the Properties of Wood Fiber-cement Composite?. BioResources 14(3): 6168-6178.https://bioresources.cnr.ncsu.edu/resources/is-wollastonite-capable-of-improving-the-properties-of-wood-fiber-cement-composite/

Haghighi-Poshtiri, A.; Taghiyari, H.R.; Karimi, A.N. 2013. The optimum level of nano-wollastonite consumption as fire-retardant in poplar wood (Populus nigra). Int J Nano 4(2): 141-151. http://doi.org/10.7508/ ijnd.2013.02.007

Karimi, A.; Haghighi-Poshtiri, A.; Taghiyari, H.R.; Hamzeh, Y.; Enayati, A.A. 2012. Effects of nano-wollastonite impregnation on fire resistance and dimensional stability of poplar wood. In The International Research Group on Wood Protection, IRG/WP 12-40595. Kuala Lumpur, Malaysia. https://www.irg-wp.com// irgdocs/details.php?8a5a2b57-159f-7300-1274-55d90472351a

Khosrviyan, B. 2009. The study of mechanical, physical, thermal and morphological properties of hybrid multi- structures and nano hybrid polypropylene wood flour/ wollastonite multi- structures (In Persian). M.S. degree thesis. Department of Natural Resource, The University of Tehran, Karaj, 103p.

Li, H.; Xiao, H.; Ou, J. 2004. A study on mechanical and pressure-sensitive properties of cement mortar with nanophase materials. Cem Concr Res 34(3): 435-438. https://doi.org/10.1016/j.cemconres.2003.08.025

Ma, X.X.; Wang, C.G. 2012. Hydration characteristics of mixture of grapevine and cement. J Nanjing For Univ 36(3): 157-159. (in Chinese) http://en.cnki.com.cn/Article_en/CJFDTotal-NJLY201203035.htm

Papadopoulos, A. 2008. Natural durability and performance of hornbeam cement bonded particleboard. Maderas-Cienc Tecnol 10(2): 93-98. https://doi.org/10.4067/S0718-221X2008000200002

Rangavar, H.; Kargarfard, A.; Hoseiny-Fard, M.S. 2016. Investigation on Effect of cement types on the cement hydration and properties of wood-cement composites manufactured using sunflower stalk (Helianthus Annuus) (In Persian). Iran J Wood Paper Sci Res 31(2): 336-348. http://dx.doi.org/10.22092/ijwpr.2016.105933

Taghiyari, H.R.; Mobini, K.; Sarvari- Samadi, Y.; Doosti, Z.; Karimi, F.; Asghari, M.; Jahangiri, A.; Nouri, P. 2013. Effects of nano-wollastonite on thermal conductivity coefficient of medium-density fiberboard. J Nanomater Mol Nanotechnol 2(1): 1-5. http://doi.org/10.4172/2324-8777.1000106 
Taghiyari, H.R.; Ghorbanali, M.; Tahir, P.M.D. 2014. Effects of the improvement in thermal conductivity coefficient by nano-wollastonite on physical and mechanical properties in medium density fiberboard (MDF). BioResources 9(3): 4138-4149. http://doi.org/10.15376/biores.9.3.4138-4149

Wei, Y.M.; Tomita, B.; Hiramatsu, Y.; Miyatake, A.; Fujii, T.; Fujii, T.; Yoshinaga, S. 2003. Hydration behavior and compressive strength of cement mixed with exploded wood fiber strand obtained by the water-vapor explosion process. $J$ Wood Sci (49): 317-326. http://doi.org/10.1007/s10086-002-0479-5

Yel, H.; Donmez Cavdar, A.; Boran Torun, S. 2020. Effect of press temperature on some properties of cement bonded particleboard. Maderas-Cienc Tecnol 22(1): 83-92. http://doi.org/10.4067/S0718$221 \times 2020005000108$ 